\title{
Sexual Health Help-Seeking Behavior among Migrants from Sub-Saharan Africa and South East Asia living in High Income Countries: A Systematic Review
}

\author{
Donna Angelina Rade ${ }^{1}$, Gemma Crawford ${ }^{2}$ (D), Roanna Lobo ${ }^{2}$, Corie Gray ${ }^{2, *(i)}$ \\ and Graham Brown 2,3 \\ 1 School of Public Health, Curtin University, Kent Street, Bentley, WA 6102, Australia; \\ d.rade@postgrad.curtin.edu.au \\ 2 Collaboration for Evidence, Research and Impact in Public Health, School of Public Health, \\ Curtin University, Kent Street, Bentley, WA 6102, Australia; g.crawford@curtin.edu.au (G.C.); \\ roanna.lobo@curtin.edu.au (R.L.); Graham.Brown@latrobe.edu.au (G.B.) \\ 3 Australian Research Centre in Sex, Health and Society School of Psychology and Public Health, \\ La Trobe University, Bundoora, VIC 3086, Australia \\ * Correspondence: corie.gray@curtin.edu.au
}

Received: 16 May 2018; Accepted: 18 June 2018; Published: 22 June 2018

\begin{abstract}
The number of migrants has increased globally. This phenomenon has contributed to increasing health problems amongst migrants in high-income countries, including vulnerability for HIV acquisition and other sexual health issues. Adaptation processes in destination countries can present difficulties for migrants to seek help from and gain access to health services. This study examined migrants' from sub-Saharan Africa (SSA) and South East Asia (SEA) sexual health help-seeking behavior in high-income countries with universal health coverage. The systematic review followed PRISMA guidelines and was registered with PROSPERO. Several databases were searched from 2000 to 2017. Of 2824 studies, 15 met the inclusion criteria. These consisted of 12 qualitative and three quantitative studies conducted in Australia, Spain, the United Kingdom, Belgium, Scotland, Ireland, and Sweden. Migrants experienced a range of difficulties accessing health services, specifically those related to sexual health, in high-income countries. Few studies described sources of sexual health help-seeking or facilitators to help-seeking. Barriers to access were numerous, including: stigma, direct and indirect costs, difficulty navigating health systems in destination countries and lack of cultural competency within health services. More culturally secure health services, increased health service literacy and policy support to mitigate costs, will improve health service access for migrants from SSA and SEA. Addressing the structural drivers for stigma and discrimination remains an ongoing and critical challenge.
\end{abstract}

Keywords: migrants; sexual health; help-seeking behavior; systematic review

\section{Introduction}

The number of migrants has been increasing globally, with an estimate of 258 million international migrants in 2017 [1]. Between 1990 and 2017, the number of international migrants increased from 152.5 million to 257.7 million-a rise of over $69 \%$ [1]. Half (51\%) of these migrants were situated in only 10 countries - nine of which are classified as high-income countries (HIC) by the World Bank, including United States of America (USA), France, Canada and Australia [2]. A documented migrant is defined as someone "who entered a country lawfully and remains in the country in accordance with 
his or her admission criteria" [3]. Australia, as an example, has a substantial proportion of documented international migrants [4] with the Australian Bureau of Statistics [4] recently reporting that the number of overseas migrants has reached its highest point in 20 years.

There are multiple and complex reasons for migration to HIC, including: safety and security, health, labour, economic inequalities between high and low-income countries, and family reunification [5-7]. There are a range of health issues associated with migration; with increased vulnerability during the migration process [8]. Research from HIC indicates migrants from low and middle-income countries (LMIC) may have different health and health care needs than the destination population [8]. This vulnerability may lead to specific problems regarding sexual and reproductive health (SRH) and service provision [9]. The complexity of migrants' diverse religions, cultural backgrounds, educational levels, migration histories, present living conditions and legal statuses may all influence their sexual health (SH), including their vulnerability for HIV acquisition [9].

Research with migrants in Australia, Canada, the United Kingdom (UK), France, Switzerland and the Netherlands highlight vulnerability for HIV acquisition, with some overseas born populations overrepresented in HIV notifications [10]. In the case of Australia, people born in sub-Saharan Africa and North and Southeast Asia have some of the highest rates of HIV diagnoses by region of birth and are overrepresented in late or advanced presentation of HIV infection [11]. It has been suggested that a range of risk factors have contributed to the higher number of HIV cases from these two regions, such as: low levels of HIV literacy; high rates of undiagnosed and therefore untreated HIV infections; significant levels of stigma attached to HIV which prevents people from being tested, treated, or from seeking information; and misconceptions that Australia is free from HIV [12].

Personal, interpersonal, social life, environmental, and cultural factors play important roles in influencing migrants' sexual health help-seeking behavior. Previous Australian research shows SEA and SSA face a range of challenges, such as the adaptation process, cultural and gender differences and norms, level of control over decision-making, lack of familiarity with the Australian health system, lack of English language proficiency and inequities in health service access, including to HIV testing [12]. Whilst not explored in this review, it is acknowledged that there are further barriers to accessing health services for undocumented migrants.

A better understanding of the facilitators and barriers faced by documented migrants from SSA and SEA in utilizing SRH services may inform the development of tailored and innovative health promotion strategies [13] and more comprehensive, appropriate, and accessible health services for migrants in high income countries. The aim of this systematic review is to explore, from the perspective of migrants, types of help-seeking behavior and the barriers and enabling factors that influence documented migrants in gaining access to SRH services and HIV testing in high income countries (such as Australia) with universal health coverage (UHC).

\section{Methods}

This systematic review was conducted according to the Preferred Reporting Items for Systematic Reviews and Meta-Analyses (PRISMA) guidelines [14]. It followed procedures previously used by other systematic reviews conducted by the research team [15-17]. The review was registered in the International Prospective Register of Systematic Reviews (PROSPERO) to ensure quality adherence, reporting and dissemination (registration number: CRD42015023330).

\subsection{Search Strategy and Information Sources}

A total of seven databases were searched: PsycINFO, MEDLINE, ProQuest, PubMed, Scopus, Global Health and Web of Science. Google Scholar was also used to verify the results of the database searches. Lastly, an examination of reference lists from the relevant studies was undertaken to assess whether database results were exhaustive.

Search terms included: (migrant*, immigra*, "sexual health", "reproductive health", "help-seeking behavio?r, "health seeking behavio? $r$ "). All relevant variations, including Medical Subject Headings 
(MeSH) [18] terms were used depending on database requirements and specifications (see Table 1). Searched fields were keywords, title, and abstract.

Table 1. Search terms and databases used in the systematic review.

\begin{tabular}{|c|c|}
\hline Databases & $\begin{array}{l}\text { PsycINFO, MEDLINE, ProQuest, PubMed, Scopus, Global Health and Web of } \\
\text { Science. }\end{array}$ \\
\hline Concept 1: Migrants & 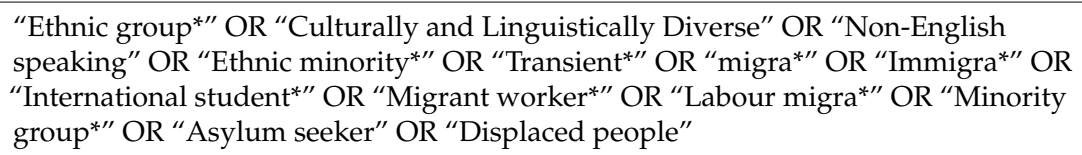 \\
\hline Concept 2: Sexual health & 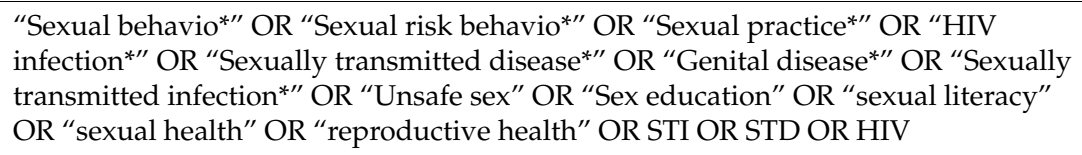 \\
\hline Concept 4: Help-seeking & $\begin{array}{l}\text { "Health seeking behavio?r" OR “Help-seeking behavio?r" OR “Health system" OR } \\
\text { "Health care" OR "Health service accessibility" OR “Health service" OR “Health } \\
\text { information" OR "Health education" OR "Social support" OR "Primary health care" } \\
\text { OR "HIV testing" }\end{array}$ \\
\hline
\end{tabular}

This review considered qualitative or quantitative evidence from primary studies related to adult migrant sexual health help-seeking behavior in HIC. For the purposes of this study, HIC were those nominated by the World Bank as Organization for Economic Co-operation and Development (OECD) countries with Gross National Income (GNI) per capita above \$12,236 [2]. Only articles with a focus on sexual health were included. Help-seeking behaviour was described as "the behaviour of actively seeking help" and included formal (e.g., from health professionals), informal (e.g., from friends and family) and self-help sources [19].This review was interested in studies of documented migrants, and studies that focused solely on undocumented migrants were not included. This was due to the fact that undocumented migrants experience unique barriers to accessing health services compared to documented migrants. Studies were incorporated if they included migrants from sub-Saharan African and Southeast Asian countries, aged above 18 years old, and residing in high income countries for more than 1 year. This review was interested in the migrant experience, and as such, articles on the perspectives of healthcare providers were not included.

The review included only studies conducted in countries that had Universal Health Coverage (UHC), such as Australia, Spain, the United Kingdom, Belgium, Scotland, the Republic of Ireland, and Sweden. Description of what UHC entails, who is entitled to UHC, and a definition of UHC, has been debated [20] and as such, there are discrepancies in its applications between countries for migrants. This review used as the definition of UHC a "health care system that provides healthcare and financial protection to more than $90 \%$ of the citizens of a particular country" [21]. Data from the Global Residence Index was used to determine countries with UHC [21]. From this list, only two HIC were without UHC - the United States of America and Saint Kitts and Nevis. It is acknowledged that UHC is often not extended to all migrants. For example, those on temporary visas (including international students and workers) in Australia are not eligible to Medicare (Australia's UHC system) [22]. Likewise, for those seeking asylum in Australia, health care is reported to have been below Australian standards, with long delays in accessing medical professionals [23]. Broader articles on help-seeking or reproductive health only were not included.

Only full text, peer-reviewed journal articles, published in English, between the years 2000-2017 were included in the review. Every study identified through the database searches was examined based on information in the abstract and title. The full text from relevant studies that met the inclusion criteria was then retrieved.

Title and abstract were screened by two reviewers for potential eligible articles. The results were then checked by another member of the team based on the inclusion and exclusion criteria. Forty-two articles were eligible. Quality appraisal was conducted by two reviewers using a checklist adapted 
from the Joanna Briggs series of assessment and review instruments [24] and the National Institute for Health and Care Excellence (NICE) Quality Appraisal Checklist [25]. Criteria considered in the quality appraisal checklist included: study population, methodology, outcomes and analysis. Meetings to discuss quality appraisal with the broader research team identified additional articles for exclusion based on the income of the host country, UHC status and migrant country of birth. Final judgment regarding the quality of selected studies was based on the overall assessment of the article, methods, and study objectives and their relevance. Studies that were excluded at this point $(n=27)$ included those without ethical approval or insufficient content on sexual health and HIV. A final 15 studies were included. Figure 1 shows the process of study selection.

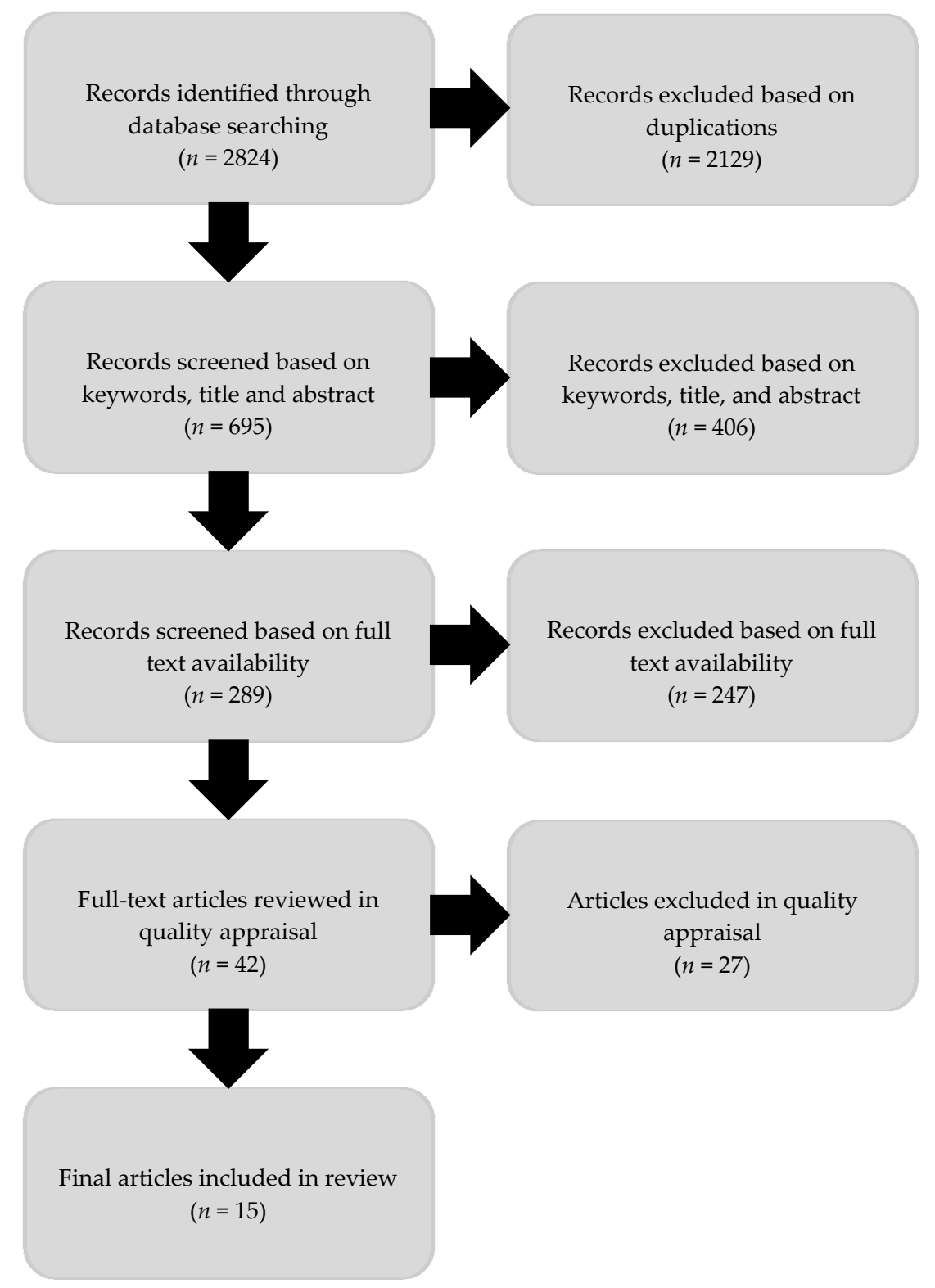

Figure 1. Flow diagram of review process.

\subsection{Data Extraction}

Two researchers independently performed data extraction on the selected articles using a standardized data extraction form [24]. The data extracted included author and title, research objective, study design, and key conclusions and recommendations. The final studies were classified 
into three broad areas: (1) Sources of sexual health help-seeking of migrants, (2) enabling factors for sexual health help-seeking behavior of migrants, and (3) barriers to sexual health help-seeking behavior of migrants.

\section{Results}

Fifteen studies met the inclusion criteria for the review (see Table 2). All selected studies included migrants from Southeast Asia and sub-Saharan African countries living in high income countries, specifically those with UHC. Of these 15 studies, seven were conducted in Australia [26-32]; two in the UK [33,34] and one study in Sweden [35], Ireland [36], Spain [37], Belgium [38], and Scotland respectively [39]. Of the 15 studies, eight studies examined migrants from sub-Saharan African countries [29,31,33,34,36,38-40]; two studies examined migrants from Southeast Asia countries [26,35]; and five studies explored migrants from mixed regions $[27,28,30,32,37]$.

Twelve of the studies were qualitative $[26,27,30-38,40]$; and three were quantitative studies [28,29,39]. Of the 12 qualitative studies, six used focus group discussions [26,27,31,33,34,38], three used in-depth interviews [32,35-37], and three used a mix of focus group discussions and interviews $[30,36,40]$. Nine of the studies included both male and female participants $[27,28,30,32-34,36,38,40]$, with the remaining six studies completed with female participants $[26,29,31,35,37,39]$. Three of the studies focused only on refugees $[26,29,30]$, and four of the studies had a mean arrival to destination country of less than five years $[27,29,35,36]$. The studies varied in participant age with the majority including participants between 18 and 60 years. Two studies included participants aged 16 and over [30,39]. Two of the studies were conducted with people living with HIV [32,37]. All studies received ethics approval from a human research ethics committee [26-40]. Results have been reported on in the following domains:

- Sources of help-seeking - sources of information for sexual health and sources for treatment.

- Facilitating factors-social support and patient-healthcare provider relationship.

- Barriers-personal factors; interpersonal and cultural factors; cultural competency of healthcare provider; healthcare cost and location; confidentiality and relationship with healthcare provider.

- Study recommendations-policy, practice (clinical and health promotion) and research. 
Table 2. General study characteristics, quality appraisal, and findings of fourteen studies addressing migrant sexual health help-seeking behavior in high income countries.

\begin{tabular}{|c|c|c|c|}
\hline Title & Research Objective & Study Design & Conclusions/Recommendations \\
\hline $\begin{array}{l}\text { Adedimeji et al. (2015) [36] } \\
\text { Increasing HIV testing among } \\
\text { African immigrants in Ireland: } \\
\text { Challenges and opportunities }\end{array}$ & $\begin{array}{l}\text { To identify barriers for African } \\
\text { migrants to access voluntary HIV } \\
\text { testing, and to assess possible } \\
\text { solutions to increase rates of HIV } \\
\text { testing among this population. }\end{array}$ & $\begin{array}{l}\text { - Setting: Ireland } \\
\text { Inclusion criteria/eligibility: Migrants from Africa, } \\
\text { lived in Ireland more than } 2 \text { years and not previously } \\
\text { diagnosed with HIV. } \\
\text { - Sample: } 60 \text { participants—-focus groups }(n=56) \text {, } \\
\text { interviews }(n=4) \text {. Mean of } 4.7 \text { years since migrating } \\
\text { to Ireland. } \\
\text { - Age range: } 18-64 \text { years old } \\
\text { - Gender: Male and female } \\
\text { - Type of study: Qualitative; semi-structured } \\
\text { interviews and focus groups } \\
\text { - Recruitment: Convenience and snowball sampling } \\
\text { - Ethical approval: Yes }\end{array}$ & $\begin{array}{l}\text { Conclusions: } \\
\text { - Barriers to HIV testing in African migrants in Ireland } \\
\text { were found, including fear of consequences of an HIV } \\
\text { diagnosis (residency status and social relations) and } \\
\text { test affordability. } \\
\text { Recommendations: } \\
\text { - Involve stakeholders (immigrant group leaders, policy } \\
\text { makers, health providers and religious leaders) in } \\
\text { interventions to increase HIV testing to ensure } \\
\text { cultural acceptability. }\end{array}$ \\
\hline $\begin{array}{l}\text { Agu et al. (2016) [27] } \\
\text { Migrant sexual health help-seeking } \\
\text { and experiences of stigmatization } \\
\text { and discrimination in Perth, Western } \\
\text { Australia: Exploring barriers and } \\
\text { enablers }\end{array}$ & $\begin{array}{l}\text { To explore barriers and enablers to } \\
\text { sexual health help-seeking } \\
\text { behaviors, and experiences of } \\
\text { stigma and discrimination among } \\
\text { migrants from sub-Saharan Africa } \\
\text { and Southeast Asia living in Perth, } \\
\text { Western Australia. }\end{array}$ & $\begin{array}{l}\text { - } \quad \text { Setting: Australia } \\
\text { Inclusion criteria/eligibility: Born in SEA or SSA, } \\
\text { - } \quad \text { lived in Australia more than one year. } \\
\text { other regions. } 45 \text { participants -21 from } 76 \% \text { of participants had arrived in } \\
\text { Australia less than } 5 \text { years. } \\
\text { - } \quad \text { Age range: } 18-50 \text { years old } \\
\text { - Gender: Male and female } \\
\text { - Type of study: Qualitative; focus groups } \\
\text { - Recruitment: Purposive and snowball } \\
\text { - } \quad \text { Eampling techniques. } \\
\text { Ethical approval: Yes }\end{array}$ & $\begin{array}{l}\text { Conclusions: } \\
\text { - Barriers and enablers to sexual help-seeking behaviors } \\
\text { included sociocultural and religious influence, financial } \\
\text { constraints and knowledge dissemination to } \\
\text { reduce stigma. } \\
\text { - Common experiences of stigma and discrimination } \\
\text { (including in health care settings) and the social and } \\
\text { self-isolation of people living with HIV. } \\
\text { Recommendations: } \\
\text { - Address stigma and discrimination in health care settings } \\
\text { - Provide culturally-appropriate sexual health knowledge } \\
\text { that is group specific rather than targeted at } \\
\text { migrants universally. }\end{array}$ \\
\hline $\begin{array}{l}\text { Akerman et al. (2017) [35] } \\
\text { Healthcare-seeking behaviour in } \\
\text { relation to sexual and reproductive } \\
\text { health among Thai-born women in } \\
\text { Sweden: a qualitative study }\end{array}$ & $\begin{array}{l}\text { To explore sexual health } \\
\text { help-seeking behaviors and views } \\
\text { of HIV among Thai women living } \\
\text { in Sweden. }\end{array}$ & $\begin{array}{l}\text { - } \quad \text { Setting: Sweden } \\
\text { Inclusion criteria/eligibility: Born in Thailand and } \\
\text { - } \quad \text { Siving in Sweden less than five years } \\
\text { - } \quad \text { Age range: } 24-50 \text { years old } \\
\text { - Gender: Female } \\
\text { - Type of study: Qualitative; in-depth, } \\
\text { - } \quad \text { Remi-structured interviews } \\
\text { - } \quad \text { Ethical approval: } Y \text { Yes }\end{array}$ & $\begin{array}{l}\text { Conclusions: } \\
\text { - Low sexual and reproductive health care use and low } \\
\text { uptake of HIV testing. Women expressed low perception } \\
\text { of risk to HIV. } \\
\text { - Barriers to healthcare included: language difficulties and } \\
\text { low knowledge about the healthcare system. This resulted } \\
\text { in a dependence on partners to access health services, or a } \\
\text { preference to seek medical help in Thailand. } \\
\text { Recommendations: } \\
\text { - Offer HIV testing as part of cervical cancer screening. } \\
\text { - Offer free health examinations to Thai migrants. }\end{array}$ \\
\hline
\end{tabular}


Table 2. Cont

\begin{tabular}{|c|c|c|c|}
\hline Title & Research Objective & Study Design & Conclusions/Recommendations \\
\hline $\begin{array}{l}\text { Drummond et al. (2011) [29] } \\
\text { Barriers to accessing health care } \\
\text { services for West African refugee } \\
\text { women living in Western Australia }\end{array}$ & $\begin{array}{l}\text { To examine barriers in accessing } \\
\text { and utilizing health services of } \\
\text { West African women refugees } \\
\text { compared to Australian women. }\end{array}$ & $\begin{array}{l}\text { - Setting: Australia } \\
\text { Inclusion criteria/eligibility: Refugee women from } \\
\text { Liberia or Sierra Leone } \\
\text { - Sample: } 51 \text { women from Liberia or Sierra Leone and } \\
\text { 100 Australian women (comparison). Women were } \\
\text { newly arrived (less than } 5 \text { years) and had lived in } \\
\text { refugee camps up to } 10 \text { years before resettlement. } \\
\text { - Age range: } 20-67 \text { years (West African), 18-90 years } \\
\quad \text { (Australian) } \\
\text { - Gender: Female } \\
\text { - Type of study: Quantitative; comparison study } \\
\text { - Recruitment: Snowball sampling } \\
\text { - } \quad \text { Ethical approval: Yes }\end{array}$ & $\begin{array}{l}\text { Conclusions: } \\
\text { - Barriers to accessing health care were negatively } \\
\text { correlated with longer residence and higher education } \\
\text { Emotional factors and service provider perceptions were } \\
\text { major barriers to access healthcare services. } \\
\text { Recommendation: } \\
\text { - Implement intensive health promotion campaigns } \\
\text { through social networks and ethnic media. }\end{array}$ \\
\hline $\begin{array}{l}\text { Dune et al. (2017) [28] } \\
\text { Culture Clash? Investigating } \\
\text { constructions of sexual and } \\
\text { reproductive health from the } \\
\text { perspective of } 1.5 \text { generation } \\
\text { migrants in Australia using } Q \\
\text { methodology }\end{array}$ & $\begin{array}{l}\text { To investigate the role of culture in } \\
\text { constructions of sexual and } \\
\text { reproductive health and health care } \\
\text { seeking behavior from the } \\
\text { perspective of } 1.5 \text { generation } \\
\text { migrants }\end{array}$ & 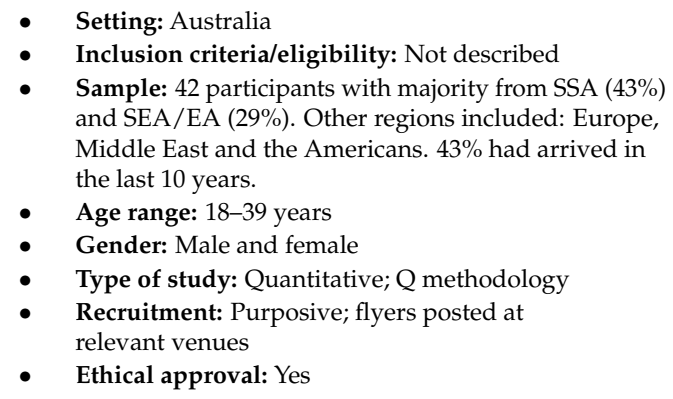 & $\begin{array}{l}\text { Conclusions: } \\
\text { - Some migrants' constructs of sexual and reproductive } \\
\text { health changed when in a new culture; others had } \\
\text { difficulty integrating new cultural values. } \\
\text { - Culture may be more easily adapted as many aspects of } \\
\text { home (e.g., political, economically, etc.) do not exist in } \\
\text { new country. Religion is portable, and may be the reason } \\
\text { for an experience of 'culture clash' for some migrants. }\end{array}$ \\
\hline $\begin{array}{l}\text { Guionnet et al. (2014) [37] } \\
\text { Immigrant women living with HIV } \\
\text { in Spain: A qualitative approach to } \\
\text { encourage medical follow-up }\end{array}$ & $\begin{array}{l}\text { To examine the facilitators and } \\
\text { barriers to medical follow-up } \\
\text { among immigrant women living in } \\
\text { Spain }\end{array}$ & 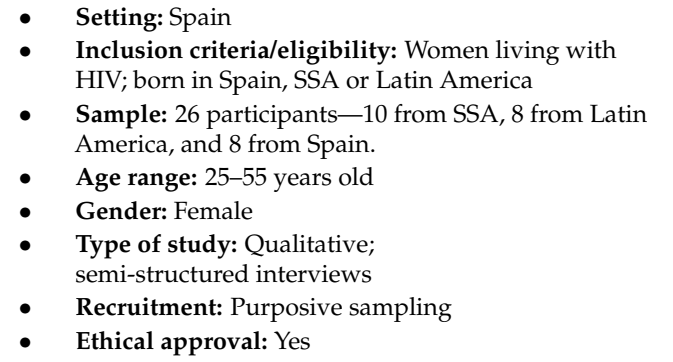 & $\begin{array}{l}\text { Conclusions: } \\
\text { - Barriers for immigrant women living with HIV in } \\
\text { continuing treatment included cultural, social, and gender } \\
\text { roles, relationship with the healthcare system, } \\
\text { and self-perception. } \\
\text { Recommendations: } \\
\text { - Health professionals to work to identify and overcome } \\
\text { barriers faced by patients in adhering to treatment }\end{array}$ \\
\hline
\end{tabular}


Table 2. Cont

\begin{tabular}{|c|c|c|c|}
\hline Title & Research Objective & Study Design & Conclusions/Recommendations \\
\hline $\begin{array}{l}\text { Korner (2007) [32] } \\
\text { 'If I Had My Residency I Wouldn't } \\
\text { Worry': Negotiating Migration and } \\
\text { HIV in Sydney, Australia }\end{array}$ & $\begin{array}{l}\text { To describe the interrelationships } \\
\text { between migration and } \\
\text { resettlement, the Australian } \\
\text { immigration system and living } \\
\text { with HIV. }\end{array}$ & $\begin{array}{l}\text { - } \quad \text { Setting: Australia } \\
\text { Inclusion criteria/eligibility: People living with HIV, } \\
\text { born in a non-English country, or speaking a language } \\
\text { other than English at home } \\
\text { - Sample: } 29 \text { participants-16 (55\%) in Asia, remainder } \\
\text { from South America and Southern Europe; } 11(38 \%) \\
\text { were permanent residents, } 12(43 \%) \text { had been in } \\
\text { Australia longer than } 10 \text { years. } \\
\text { - } \quad \text { Age range: } 29 \text { to } 58 \text { years } \\
\text { - Gender: Male and female } \\
\text { - Type of study: Qualitative; interviews } \\
\text { - Recruitment: Purposive sampling via a } \\
\quad \text { non-government organisation and a sexual } \\
\text { - } \quad \text { Ethical approval: Yes }\end{array}$ & $\begin{array}{l}\text { Conclusions: } \\
\text { - Main issue faced by migrants living with HIV } \\
\text { - } \quad \text { Uns migration } \\
\text { treatment, health care and support. } \\
\text { Recommendations: } \\
\text { - } \quad \text { Reduce barriers to accessing health services, including } \\
\text { reviewing the practice of rejecting permanent residency } \\
\text { applications of people living with HIV } \\
\text { - Address HIV-related stigma in migrant communities }\end{array}$ \\
\hline $\begin{array}{l}\text { Lindkvist et al. (2015) [40] } \\
\text { Fogging the issue of HIV-Barriers } \\
\text { for HIV testing in a migrated } \\
\text { population from Ethiopia and Eritrea }\end{array}$ & $\begin{array}{l}\text { To identify barriers faced by } \\
\text { Eritrean and Ethiopian migrants in } \\
\text { Stockholm, Sweden for HIV } \\
\text { testing. }\end{array}$ & $\begin{array}{l}\text { - } \quad \text { Setting: Sweden } \\
\text { Inclusion criteria/eligibility: Born in Ethiopia } \\
\text { or Eritrea } \\
\text { - Sample: } 28 \text { participants; focus groups }(n=21), \\
\text { interviews }(n=7) \text {. Arrival in Sweden ranged from } 2 \text { to } \\
\quad 25 \text { years. } \\
\text { - } \quad \text { Age range: Age not reported } \\
\text { - Gender: Male and female } \\
\text { - Type of study: Qualitative; focus groups } \\
\text { and interviews } \\
\text { - } \quad \text { Recruitment: Purposive sampling } \\
\text { - } \quad \text { thical approval: Yes }\end{array}$ & $\begin{array}{l}\text { Conclusions: } \\
\text { - Main barrier was 'fogging the issue of HIV'-categorised } \\
\text { as hiding the truth, living in denial and seeking help } \\
\text { outside the healthcare system. This was due to distrust of } \\
\text { the healthcare system and fearing the consequences of } \\
\text { living with HIV. } \\
\text { Recommendation: } \\
\text { - Provide culturally appropriate information on } \\
\text { HIV-related issues, in combination with offers of HIV } \\
\text { testing early on arrival to Sweden. }\end{array}$ \\
\hline $\begin{array}{l}\text { Manirankunda et al. (2009) [38] } \\
\text { "It's better not to know": Perceived } \\
\text { barriers to HIV voluntary counselling } \\
\text { and testing among sub-Saharan } \\
\text { African migrants in Belgium }\end{array}$ & $\begin{array}{l}\text { To examine the barriers, needs, and } \\
\text { perceptions of HIV voluntary } \\
\text { counselling and testing (VCT) } \\
\text { among sub-Saharan African } \\
\text { migrants in Belgium }\end{array}$ & $\begin{array}{ll}\text { - } & \text { Setting: Belgium } \\
\text { - } & \text { Inclusion criteria/eligibility: Identified as SSA; } \\
& \text { English or French speaking. } \\
\text { - } & \text { Sample: } 70 \text { participants. Mean duration of stay } \\
& 8.5 \text { years. } \\
\text { - } & \text { Age range: } 18-49 \text { years } \\
\text { - } \quad \text { Gender: Male and female } \\
\text { - } \quad \text { Type of study: Qualitative; focus groups } \\
\text { - } \quad \text { Ethical approval: Yes }\end{array}$ & $\begin{array}{l}\text { Conclusions: } \\
\text { - Multiple barriers to VCT identified including: fear of } \\
\text { dying of AIDS, fear of stigma or discrimination and low } \\
\text { perceived risk of acquisition. } \\
\text { Recommendation: } \\
\text { - Implement VCT with pre- and post-test counselling, } \\
\text { including via health services and via community } \\
\text { outreach testing. }\end{array}$ \\
\hline
\end{tabular}


Table 2. Cont

\begin{tabular}{|c|c|c|c|}
\hline Title & Research Objective & Study Design & Conclusions/Recommendations \\
\hline $\begin{array}{l}\text { McMichael and Gifford (2009) [30] } \\
\text { "It is Good to Know Now ... Before } \\
\text { it's Too Late": Promoting Sexual } \\
\text { Health Literacy Amongst Resettled } \\
\text { Young People With Refugee } \\
\text { Backgrounds }\end{array}$ & $\begin{array}{l}\text { To explore young refugees' } \\
\text { accessibility to health information }\end{array}$ & $\begin{array}{l}\text { - Setting: Australia } \\
\text { - Inclusion criteria/eligibility: From } \\
\text { refugee background. } \\
\text { - Sample: } 142 \text { participants-interviews }(n=14) \text {, focus } \\
\text { groups (n-128). Most participants were from Iraq, } \\
\text { Afghanistan, Burma, Sudan, Liberia and the Horn } \\
\text { of Africa. } \\
\text { - } \quad \text { Age range: } 16-25 \text { years } \\
\text { - Gender: Male and female } \\
\text { - Type of study: Qualitative; focus group discussions } \\
\text { and interviews } \\
\text { - Recruitment: Purposive sampling } \\
\text { - Ethical approval: Yes }\end{array}$ & $\begin{array}{l}\text { Conclusions: } \\
\text { - Similar barriers were found to health service access as } \\
\text { other young people } \\
\text { - Experiences of forced migration, displacement, and } \\
\text { resettlement brings additional challenges. } \\
\text { Recommendation: } \\
\text { - Improve accessibility of sexual health services to reduce } \\
\text { poor sexual health outcomes and increase sexual } \\
\text { health literacy. }\end{array}$ \\
\hline $\begin{array}{l}\text { Rogers and Earnest (2014) [31] } \\
\text { A cross-generational study of } \\
\text { contraception and reproductive } \\
\text { health among Sudanese and } \\
\text { Eritrean women in Brisbane, } \\
\text { Australia }\end{array}$ & $\begin{array}{l}\text { To assess knowledge and access to } \\
\text { contraception and reproductive } \\
\text { health of mothers and daughters } \\
\text { from Sudanese and Eritrean } \\
\text { backgrounds living in Brisbane }\end{array}$ & 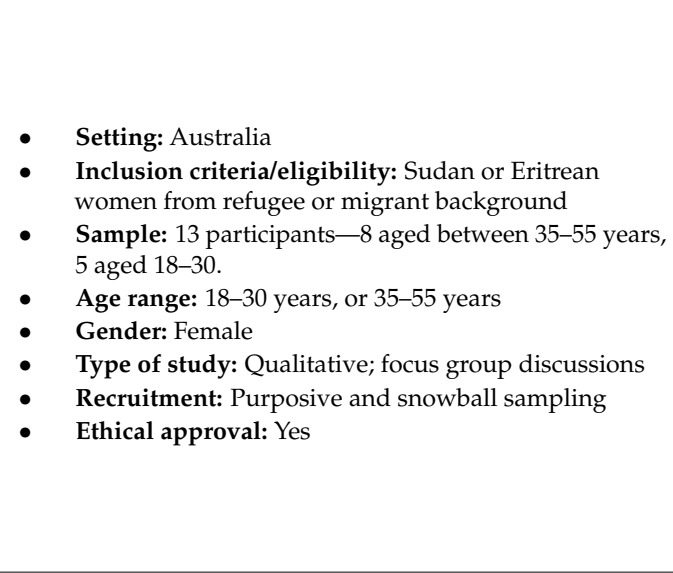 & $\begin{array}{l}\text { Conclusions: } \\
\text { - A range of barriers found to health service access and } \\
\text { contraceptive use included: lack of cultural competency } \\
\text { and ineffective communication by health care workers; } \\
\text { poor knowledge of health care system and } \\
\text { intergenerational culture clash in relation to sexual health } \\
\text { education in the home. } \\
\text { Recommendations: } \\
\text { - Provide sexual health information for new migrants } \\
\text { during process of resettling } \\
\text { - Develop partnerships between health care professionals } \\
\text { and CaLD communities } \\
\text { Provide translated health information and access } \\
\text { to interpreters } \\
\text { Design culturally sensitive strategies for parents to } \\
\text { communicate with their children about sexual health and } \\
\text { enable parent-daughter transfer of health information. }\end{array}$ \\
\hline $\begin{array}{l}\text { Shangase and Egbe (2014) [33] } \\
\text { Barriers to accessing HIV services } \\
\text { for Black African communities } \\
\text { in Cambridgeshire, } \\
\text { the United Kingdom }\end{array}$ & $\begin{array}{l}\text { To examine barriers faced by Black } \\
\text { African communities to accessing } \\
\text { HIV healthcare services. }\end{array}$ & $\begin{array}{l}\text { - } \quad \text { Setting: United Kingdom } \\
\text { Inclusion criteria/eligibility: From } \\
\text { African communities. } \\
\text { - Sample: } 30 \text { participants; most aged in their twenties } \\
\text { and thirties } \\
\text { - } \quad \text { Age range: } 21-65 \text { years } \\
\text { - } \quad \text { Tender: Male and female } \\
\text { - } \quad \text { Recruitment: Purposive sampling } \\
\text { - } \quad \text { Ethical approval: Yes }\end{array}$ & $\begin{array}{l}\text { Conclusions: } \\
\text { - A range of barriers found including language, limited } \\
\text { knowledge of HIV, preference for traditional medicines } \\
\text { and lack of cultural diversity among health } \\
\text { service workers. } \\
\text { Recommendations: } \\
\text { - Plan health services considering cultural diversity, } \\
\text { including use of traditional medicine } \\
\text { - Ensure HIV workforce undertakes cultural competency } \\
\text { training, and is culturally diverse. }\end{array}$ \\
\hline
\end{tabular}


Table 2. Cont

\begin{tabular}{|c|c|c|c|}
\hline Title & Research Objective & Study Design & Conclusions/Recommendations \\
\hline $\begin{array}{l}\text { Thomas et al. (2010) [34] } \\
\text { "If I cannot access services, then there } \\
\text { is no reason for me to test": the } \\
\text { impacts of health service charges on } \\
\text { HIV testing and treatment amongst } \\
\text { migrants in England }\end{array}$ & $\begin{array}{l}\text { To examine the influence of } \\
\text { England's government health } \\
\text { policy on migrants' health seeking } \\
\text { and HIV testing. }\end{array}$ & $\begin{array}{l}\text { - } \quad \text { Setting: United Kingdom } \\
\text { Inclusion criteria/eligibility: Living in the UK as } \\
\text { a migrant } \\
\text { - Sample: } 70 \text { participants from South Africa, } \\
\text { - Zimbabwe, and Zambia } \\
\text { - } \quad \text { Age range: Above } 18 \text { years } \\
\text { - } \quad \text { Type of study: Qualitative; focus group discussions } \\
\text { - Recruitment: Purposive sampling } \\
\text { - } \quad \text { Ethical approval: Yes }\end{array}$ & $\begin{array}{l}\text { Conclusions: } \\
\text { - Changes in policy resulted in difficulties in accessing } \\
\text { healthcare services due to cost and difficultly registering. } \\
\text { Recommendations: } \\
\text { - Reverse the policy changes made } \\
\text { - Provide clear information and guidelines to both migrants } \\
\text { and health workers in regards to accessing free } \\
\text { health services. }\end{array}$ \\
\hline $\begin{array}{l}\text { Yakubu et al. (2010) [39] } \\
\text { Sexual health information and } \\
\text { uptake of sexual health services } \\
\text { by African women in Scotland: } \\
\text { A pilot study }\end{array}$ & $\begin{array}{l}\text { To identify sources of sexual health } \\
\text { information sought by African } \\
\text { women in Scotland. }\end{array}$ & 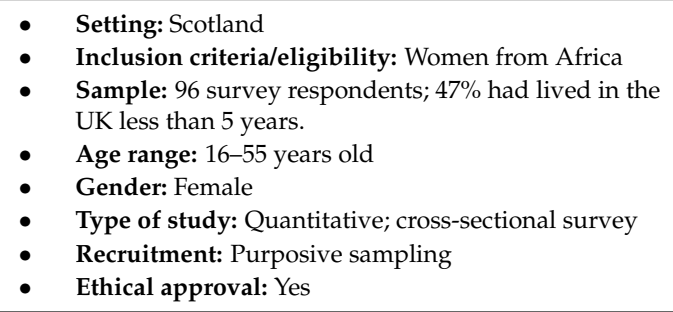 & $\begin{array}{l}\text { Conclusions: } \\
\text { - Poor knowledge of STIs and HIV and low uptake of } \\
\text { sexual health services and regular screening. } \\
\text { Recommendation: } \\
\text { - Develop collaboration between African communities in } \\
\text { Scotland with the sexual health services to develop better } \\
\text { HIV prevention program. }\end{array}$ \\
\hline $\begin{array}{l}\text { Ussher et al. (2012) [26] } \\
\text { Purity, privacy and procreation: } \\
\text { Constructions and experiences of } \\
\text { sexual and reproductive health in } \\
\text { Assyrian and Karen women } \\
\text { living in Australia }\end{array}$ & $\begin{array}{l}\text { To assess experiences of Karen and } \\
\text { Assyrian woman refugees in } \\
\text { utilizing SRH services in Australia }\end{array}$ & $\begin{array}{l}\text { - Inclusion criteria/eligibility: Women from Karen and } \\
\text { Assyrian communities who arrived as refugees } \\
\text { - Setting: Australia } \\
\text { - Sample: } 42 \text { participants-28 (67\%) from Karen } \\
\text { communities. Karen participants had arrived on } \\
\text { average } 3.5 \text { years ago. } \\
\text { - Age range: } 25-45 \text { years } \\
\text { - } \quad \text { Gender: Female } \\
\text { - } \quad \text { Recruitme of study: Qualitative; focus group discussions } \\
\text { - Ethical approvirposive sampling }\end{array}$ & $\begin{array}{l}\text { Conclusions: } \\
\text { - Constructions and experiences of sexual health were } \\
\text { closely tied to cultural, religious and gendered } \\
\text { family views. } \\
\text { Recommendations: } \\
\text { - Further research to explore interaction of gender, culture } \\
\text { and migration process in the construction of sexual health }\end{array}$ \\
\hline
\end{tabular}




\subsection{Sources of Sexual Health Help-Seeking}

Of the 15 included studies, four studies reported findings on the sources of sexual health information sought by migrants from sub-Saharan African and Southeast Asian countries living in high-income countries [27,30,33,35,39].

Migrants used a range informational sources including health professionals, TV and radio, books and magazines, and friends and family. Generally, there was a preference for information to come from a professional source; however, this was not easily accessed [30,39]. For example, in a survey with African women in Scotland ( $n=92)$, Yakubu et al., found that the majority of women received SH information from books and magazines (79\%); TV/radio (76\%); and friends and family $(70 \%)$; and only around a third from a family doctor (35\%) [39]. However, preferences on where to receive information were firstly from a doctor (57\%), a sexual health clinic $(46.6 \%)$ and $\mathrm{TV} /$ radio $(39.7 \%)$, with only a small proportion wishing to receive information from family and friends $(27 \%)$.

A study by McMichael and Gifford used focus groups and interviews to explore access to sources of sexual health information and services among young ( $16-25$ years old) refugees in Australia $(n=142)$. They found a preference for participants to seek sexual health information from doctors, who were seen as having expertise and the ability to provide accurate information [30]. However, it was highlighted that the participants only sought help from a doctor in relation to symptoms of an STI, for contraception or for an unplanned pregnancy [30]. In addition, participants tended to discuss sexual health with their peers, however, they reflected that they could not rely on their friends' information because it was sometimes unreliable and incomplete. Participants found it difficult to seek SH information from their parents due to religious and cultural factors; fear of judgement; and dislike for responses that focused on warnings or personal responsibility [30].

In this study, media (including radio and TV) and written material (books and magazines) were common sources of information; however, young refugees suggested that some of these materials presented were uninteresting, or provided exaggerated or inconsistent information [30]. Instead, the study found preference for using the internet as a source of sexual health information, as users can remain anonymous [30].

In semi-structured interviews with Thai women in Sweden $(n=19)$, Akerman et al. found that most women would discuss sexual health information with their partner in the first instance [35]. In the case of contraceptives or other women's health issues (i.e., pregnancy), women would seek information from other women, including Thai friends, family, or their partner's family [35]. Women also used the internet before visiting their GP (accessed via their partners) [35].

A survey by Drummond et al. with newly arrived (less than 5 years) West African women in Australia $(n=51)$ found that most women would access a medical clinic $(94 \%)$ or a hospital clinic $(67 \%)$ if they thought they had a STI [29]. They were least likely to seek treatment from a religious leader (8\%), self-help groups, family or friends or traditional healers (all 10\%) [29].

\subsection{Facilitators for Sexual Health Help-Seeking Behavior}

Of the 15 studies, five studies described factors that facilitated migrants to access and utilize sexual health services $[27,28,30,35,37]$; however, these were often not the main research objective.

In some studies, participants described attending healthcare services if there was a physical symptom that they could not fix [30,35]. Social support was not only a source of information on SRH, but also supported help-seeking behavior [27,28,35,37]. In semi-structured interviews by Guionnet et al. with women living with HIV in Spain $(n=26)$, participants reflected that having the support of loved ones assisted them to adhere to treatment, process the information from their doctor and encouraged them to continue their treatment [37]. Likewise, positive relationships with their healthcare provider encouraged participants to attend appointments and adhere to treatment. Positive interaction included: the doctor being an expert on the issue, providing emotional support and translation of scientific terms to lay language [37]. A trustworthy relationship with healthcare providers was also found to facilitate access to sexual health services [30,37]. 


\subsection{Barriers to Sexual Health Help-Seeking Behavior}

Fourteen of the 15 studies highlighted factors that inhibited migrants from accessing health services in high income countries [27-36,38,40]. From these studies, the following barriers to accessing health care services were described.

\subsubsection{Personal Factors}

Studies indicated that many migrants from sub-Saharan African and Southeast Asian countries had inadequate information about the health system in destination countries and experienced difficulty navigating access, such as how to make appointments or knowing the necessary documents required $[27,32,34,35,40]$. Poor knowledge and understanding of primary healthcare also limited migrants' access $[30,38]$. In addition, many studies reported a lack of knowledge of available SRH services and their location $[27,33,35,38]$.

\subsubsection{Interpersonal and Cultural Factors}

Eight of the 15 studies examined interpersonal factors preventing migrants from seeking help from health services $[26,27,29,30,33,34,36,38]$. Barriers cited by study participants were: feeling afraid of being judged by the health provider; feeling afraid and ashamed about what other people would think; and feeling embarrassed to discuss sexual health $[26,27,29,30,36,40]$. In a study by Drummond et al., participants who were asked about accessing services for an STI expressed concern about losing their job, being afraid of treatment and medication used, and were of the belief they could cope with the problem themselves [29].

In focus groups ( $n=70$ participants) by Manirankunda et al., sub-Saharan African migrants living in Belgium expressed HIV-related stigma, guilt and shame, which included a belief that people living with HIV were "at fault" for their diagnosis [38]. This type of stigma resulted in participants feeling that they were not at risk (as they had not engaged in 'bad' behavior) or avoiding testing due to fear of being diagnosed [38]. Additionally, in focus groups and interviews ( $n=60$ participants) by Adedimeji et al., sub-Saharan African participants living in Ireland expressed concern about the perception that HIV is only for "people from Africa", which created feelings of mistrust and suspicion among their own migrant communities [36]. Participants also reflected that HIV stigma was an issue, particularly among religious and community leaders. This resulted in gossip surrounding the HIV diagnosis of an individual, and in the individual feeling isolated and unsupported by their community. These experiences had a negative impact on people's willingness to test for HIV [36].

Likewise, there was a perception among participants in a number of studies that a sexual health issue (such as a pregnancy outside of marriage or a HIV diagnosis) would result in social isolation $[26,38,40]$. Guionnet et al. found that women living with HIV did not wish to disclose their status due to fear of being socially rejected, fear of being labelled as 'positive' or associated with negative stereotypes, and fear of hurting loved ones [37]. All women who did not disclose their status to a loved one stopped treatment [37]. In focus groups and interviews by Lindkvist with migrants from Ethiopia and Eritrea living in Sweden $(n=28)$, fear of being known to be living with HIV resulted in people not telling loved ones about their diagnosis and travelling to other cities for testing and treatment [40].

In a quantitative study using $Q$ methodology $(n=42)$, Dune et al. found that for migrants living in Australia, perception by others influenced help-seeking behavior [28]. Lack of support for issues such as STIs and having sex outside of marriage made people reluctant to seek professional care or seek appropriate resources (i.e., condoms) [28,30,37,40]. Focus groups by Roger et al. with Sudanese and Eritrean mothers and daughters in Australia highlighted a lack of discussion around SRH topics in their communities, with sexual health considered taboo [31]. As a result, many women were hesitant to discuss sexual health with a healthcare provider and had difficultly using the correct terms for SRH [31]. This finding was similar across a number of other studies $[26,27,30]$. 
In focus groups with refugee women from Karen $(n=42)$ living in Australia, Ussher et al. found conflict between refugees' culture and beliefs and Australia's approach to sexual education [26]. While older women expressed concern that teaching young girls about sexual health would encourage sex outside marriage, they found it difficult to control access to movies featuring representations of sex, sexual health education at school and interaction with sexually active friends. For young women, the taboo nature of sexual health made them reluctant to seek information or access services regarding their sexual health.

For women from Thailand in the Åkerman et al. study, access to health services was delayed or avoided due to perceived dependence on their male partner [35]. The male partner was first consulted, before he would then arrange for his female partner to attend a health service. Likewise, in interviews with migrants living with HIV in Australia $(n=29)$ in a study by Korner et al., women also indicated dependence on their husband to arrange healthcare appointments [32].

In some studies, participants preferred the use of traditional medicines-either entirely, or in conjunction with prescribed medication [33,34,38]. Participants also reported self-medicating until they were "really" sick, before seeking professional treatment [34].

\subsubsection{Cultural Competency of Healthcare Provider}

Cultural competency issues were reported as barriers in eight studies [27,31-33,35-37]. As an example, in a study by Adedimeji et al., sub-Saharan African migrants living in Ireland expressed reluctance to seek healthcare due to perceived poor service from providers; with the perception that health providers were insensitive and arrogant [36]. This was instigated by a lack of appropriate interpreter services and a perception that providers believed "everyone from Africa is living with HIV", resulting in perceived discrimination [36]. This was also a concern expressed in focus groups by Agu et al., with migrants from SSA and SEA in Australia $(n=45)$, with some participants believing they had been tested without giving consent [27]. Testing without consent was also the experience for some migrants diagnosed with HIV in Australia in the Korner et al. study, who indicated that they were not aware they had been tested when they found out their HIV diagnosis [32]. Experiences of discrimination in the destination country outside of healthcare services also limited willingness to seek professional services [27,33].

The cultural background of a service provider was an important factor in accessing health services $[31,33]$. In a study by Shangase and Egbe, focus group discussions with Africans living in the UK $(n=30)$ found that participants perceived a "negative attitude" from healthcare providers based on their ethnicity [33]. Migrants in some studies suggested that people outside their own culture would be unable to understand their specific needs and would not be in a position to help navigate them through the differences in culture [31,33]. Dune et al. found that participants reported a difference in the culture of their country of origin to Australia in relation to SRH. The study highlighted a belief among participants that healthcare providers were not equipped to deal with their unique needs [28]. Several studies also described the importance of the gender of the healthcare provider, with many women unwilling to discuss sexual health with a male [31,33].

Additionally, a number of studies identified that language was a barrier [30-33,35,37,40], in that either a provider would not use simple descriptions, or an appropriate interpreter was not available or offered. This resulted in confusion around diagnosis and treatment, including correct dosage [33]. In the Åkerman et al. study with Thai women living in Sweden, male partners were often their interpreter, although they also struggled with the language used in consultations [35]. Participants in this study also expressed a preference to seek healthcare in their country of origin, due to the barriers experienced in accessing their destination country's health system [35].

In a study by Lindkvist with migrants from Ethiopia and Eritrea living in Sweden, some participants described the misuse of interpreters [40]. Participants described being provided an interpreter without being consulted on whether they needed one which was experienced as an 
insult. Issues arose when interpreters had conflicting translations, or provided incomplete translation, which created further confusion [40].

\subsubsection{Healthcare Cost and Location}

Five of the 15 studies found that the cost of healthcare and location were factors that inhibited migrants from accessing health services [27,29,34,36,38].

Adedimeji et al. reported that the cost for GP-provided HIV testing, approximately 40-50 Euros, was the largest barrier to testing for participants [36]. Many participants self-identified as having a low-income, but were not eligible for a medical card (for low-cost health services) [36]. For those able to access government funded health services, there were long waiting times, which resulted in missed opportunities for early diagnosis and linkages to care [36]. Focus groups with sub-Saharan African migrants $(n=70)$ in England by Thomas et al., identified instances of individuals using false identities in order to access free health services [34].

Several studies also found that beyond the cost of consultation, there were other costs experienced by migrants in accessing healthcare [34,36]. These included contraception, pharmaceuticals, time off work, childcare and transport [36-38]. In the study by Thomas et al., participants reported importing medication from their country of origin due to the cheaper price [34]. Likewise, in a study by Korner et al., temporary residents living with HIV in Australia indicated they were unable to afford HIV treatment and instead imported treatment from their country of origin [32].

Location of health services was also highlighted as a factor inhibiting access to testing $[36,37,40]$. Adedimeji et al. reported that most participants were accustomed to seeking treatment from main hospitals, and were unaware there were several private HIV testing services in the capital city of Ireland (Dublin) [36]. The respondents of the study were opposed to accessing treatment in the hospitals due to perceived lack of privacy [36].

\subsubsection{Confidentiality and Relationship with Healthcare Provider}

Seven of 15 studies addressed the healthcare provider and patient relationship [27,28,30,32-34,36].

In a number of studies, participants expressed concern about the confidentiality of their consultation $[27,30,31,36,37,40]$, with some preferring a person outside the community to conduct testing. Additionally, participants in some studies expressed concern about an HIV diagnosis reported to the government or immigration authorities, which they perceived would result in them being deported $[27,32,34,36,38]$.

Negative relationships and previous negative experiences with healthcare providers also limited uptake of health services and testing [37].

\subsection{Study Recommendations}

Fourteen of the 15 studies made recommendations relating to policy, health promotion and clinical practice and research. Recommendations generally related to improvements in clinical practice or for interventions to increase education and access to services [27,29-33,36,37,39,41], such as outreach HIV testing, increased sexual health education, addressing HIV-related stigma, or cultural competency training of clinical staff. Recommendations for policy are generally related to cost of health services and promoting free services $[34,35,40]$, or development of migration policies for people living with HIV [32]. Recommendations for research centered on the need for better understanding of the construction of health and sexual health among migrants and additional barriers to accessing sexual health services $[26,28]$.

\section{Discussion}

There is an upward trend in the number of migrants moving to high income countries [42]. As a result, the number of health issues experienced by SSA and SEA migrants living in those countries has increased, including increases in STIs, HIV and other SRH problems. In many countries, there is 
concern about delayed access for SRH issues, particularly in relation to late diagnosis of HIV [43-45]. Despite these concerns, there are limited peer-reviewed studies assessing SSA and SEA migrant sexual health help seeking behavior in high income countries. This review explored sources of information on sexual health and the barriers and facilitators influencing SSA and SEA migrants to gain access to $\mathrm{SH}$ services and testing in high income countries. The review identified 15 peer-reviewed articles that met the inclusion criteria published between 2000 and 2017. The articles selected identified a range of barriers, and to a lesser extent, facilitators and sources of help-seeking across a number of levels.

\subsection{Overview of Findings}

Few articles described sources of help-seeking in this review. For most migrants, healthcare providers were often considered to be the preference for information on SRH [27,30,39]. However, issues relating to access to health services, or a reluctance to discuss sexual health topics, resulted in limited knowledge transfer from these 'trusted' sources [30,39]. Combined with low levels of access to trusted sources, several studies identified topics of sexual health as being taboo-particularly for young people who were unmarried [26,27,31]. This contributed to low levels of knowledge on sexual health (mainly on safe sex practices) [46]. Indeed, previous research in Australia has identified lower knowledge on a broad range of sexual health topics among SSA and SEA migrants [47-51]. Knowledge regarding transmission and the process of testing for HIV has been shown to increase rates of testing [52,53].

This review identified very few enabling factors to accessing SRH services for SSA and SEA migrants. For most studies, symptoms relating to an SRH issue were most often the motivator for seeking professional help, which is problematic in regards to STIs and BBVs that can be asymptomatic for a period of time, such as HIV. This is consistent with previous research which has identified a reluctance to seek professional help unless physical symptoms are present, for both sexual health issues and other physical and mental health issues $[29,44,52,54]$.

Barriers to sexual health help seeking were commonly reported and were mostly consistent within this review. The main barriers identified included: low knowledge of healthcare system in the destination country and where to access SRH services; the taboo nature of SRH within communities and lack of perceived social support; lack of cultural competency within the healthcare system; the cost and location of healthcare and concerns of confidentiality [27-36,38].

In some studies, perceived shame and stigma relating to HIV and STIs limited uptake of health services, even when symptoms were apparent. Expectations of community isolation for issues such as HIV, STIs and unplanned pregnancy contributed to low levels of testing and interactions with healthcare providers $[29,31]$. In the case of HIV, there was a perception that HIV only happened to 'bad' people, which lowered individual perception of risk [55]. Previous studies have identified the important role that addressing stigma and increasing social support has in improving knowledge, safe sex behavior and improving sexual health service uptake [44,52,56-58].

For the most part, studies in this review identified a lack of responsiveness within health systems to address the needs of migrants as well as low levels of cultural competency among healthcare providers. Difficulties navigating the healthcare system, booking appointments and knowing how to link into health services were described in this review. Pathways to care are often quite different between origin and destination countries and migrants may bring expectations of health services to their new country $[59,60]$. The perceived culture regarding SRH between origin and destination country are often conflicted for migrants, with 'Western' countries suggested to be generally more liberal in their approach $[28,59]$. In some cases, a perceived invisibility of community within healthcare services limited uptake. Non-community members were perceived as being unable to help navigate cultural differences, creating difficulty in accessing services [33]. For some sub-Saharan African migrants, this was evidenced by preferences for traditional medication and expressed mistrust of 'Western' medicine [33]. In previous studies, general practitioners have identified gaps in their own knowledge and understanding of culture, which have negatively impacted on their delivery of care [61]. There is 
a need for health systems and providers to be able to understand and engage with cultural beliefs and practices, to better address the SH of migrants in their destination country [59,62].

In some studies, migrants perceived healthcare providers to be discriminatory or unable to address language barriers [30-33,35,37,40]. Sub-Saharan African migrants reported feeling 'targeted' by healthcare providers in relation to HIV, who were perceived as assuming "everyone from Africa is living with HIV" [36] and incidences of lack of consent to test for HIV were reported [27,32]. Additionally, where language was a barrier, studies identified the lack of interpreter services, and partners or other family members being used instead. In many cases, healthcare providers were criticized for using overly complicated or scientific terms, rather than lay language [30-33,35,37,40]. Previous research has identified healthcare providers as being integral to facilitating access to health services, and encouraging BBV and STI testing [62]. It is therefore critical that healthcare providers have the cultural competency to build positive, trusting relationships with migrant patients and have adequate resources (such as interpreters or bicultural workers) to support engagement and perceived cultural security $[60,61,63]$.

\subsection{Implications for Health Promotion, Clinical Practice, Policy and Research}

This review highlighted a number of considerations for practice, policy and research. These implications are based on the results and recommendations made in the included studies, unless otherwise stated. These implications are broad, acknowledging that sub-Saharan Africa and Southeast Asian migrants are not homogenous and have a range of experiences that influence barriers and facilitators to help seeking. As recommended by a number of articles from this review, community involvement is critical in the uptake of strategies to improve access to sexual health services to address unique barriers $[64,65]$.

\subsubsection{Implications for Research}

Studies discussed the differences in cultural beliefs and practices regarding health, preventative health and sexual health. A better working knowledge of communities' understanding of health and health behaviors is needed to tailor health services and health promotion interventions $[44,66]$. Future research should consider segmentation of migrant groups by country of birth, gender, age and other relevant factors to better identify and address specific issues for priority groups.

Many of the studies described barriers to health services, with very little discussion on the sources of or facilitators to help-seeking. Better understanding of what works and why is needed, with a focus on successful interventions in health promotion, service delivery and policy changes [36]. Research that focuses on the pathways of care for migrants in seeking help for sexual health issues will provide better working knowledge of experiences of testing and treatment [67].

\subsubsection{Implications for Health Promotion Practice}

A number of studies made recommendations regarding sexual education, including safe sex practices. All these studies stressed the importance of culturally-appropriate material and delivery of information [27,36]. Indeed, there is need for health promotion interventions to consider the role of culture, sexuality, resettlement process, understanding of preventative health and gender norms in sexual health help-seeking $[35,44,60,66]$. Previous research with healthcare providers have also acknowledged the need for resources to extend beyond language, and to also consider cultural factors [68]. Points of education recommended included: school-based education [30], during the settlement process [31,35], and social and ethnic media and community events [58].

The role of community and social support was acknowledged in some studies [36]. Studies also highlighted a need for direct involvement of affected communities in the development of targeted prevention and testing programs [39]. Recommendations included involving community and religious leaders in delivery of sexual education and in addressing stigma and judgment associated with unplanned pregnancy, STIs and HIV within communities. Additionally, developing partnerships 
between communities, healthcare services and health promotion organisations may help develop trust and facilitate access to relevant services by migrants [31]. Diversifying opportunities to access sexual health services may also increase help-seeking behavior [69]. Community-based testing for HIV, STI and hepatitis B have been successful [70], particularly in conjunction with information sessions from healthcare providers [38].

\subsubsection{Implications for Clinical Practice}

Access to health services and cultural competency of services were the most cited barriers to help-seeking. As global migration continues to increase, there is a need for countries and health services to be more responsive to the needs of their culturally diverse populations. This should be considered in planning health services to ensure that pathways of care are clear and accessible, there is a diversity of staff (both ethnic group and gender), appropriate interpreters and bilingual workers are accessible when required, and staff have cultural competency training $[27,33,60,63,66]$. Sufficient time must also be available to explain confidentiality and privacy, health concepts, procedures and treatment options fully, and to listen to and discuss concerns regarding cultural practices and beliefs $[33,36]$.

While not a focus of this review, other studies have cited low knowledge of priority populations for specific sexual health issues, such as HIV and hepatitis B, among healthcare providers [61,67]. Additional training, or systems to prompt sexual health discussions, may be a consideration [41]. However, identifying high risk populations may result in communities feeling 'targeted', or reify existing differences [36]. Accordingly, strategies to minimize this need to be considered with relevant communities.

\subsubsection{Implications for Policy}

Cost and location were frequent barriers to accessing health services. Consequently, direct and indirect (i.e., transport, time off work, childcare etc.) costs of access need to be considered by governments in planning the delivery of health services [36]. Experiences of migrants not being eligible for low-cost health service within countries with universal health coverage, particularly in the case of the UK [34], questions whether UHC is accessible for all people within a country [20]. In other cases, where migrants are able to access UHC, issues may pertain to the location of free health services, difficultly in applying for low-cost health care, differences in gender norms in relation to sexual behavior and help-seeking decision making, experiences of stigma and discrimination or lack of clear pathways of care $[44,60,66]$. Relevant issues need to be identified for specific populations of migrants to encourage uptake of services.

In many of these studies, documented migrants expressed concern regarding deportation, particularly in relation to HIV. Implications of an HIV diagnosis need to be made clearer in cases of mandatory testing (such as in Australia) [27], to avoid creating additional barriers to healthcare access [32].

\subsection{Study Design and Reporting Strengths and Limitations}

Most studies indicated methodological limitations of the research. Limitations that were frequently reported in included studies were: lack of interpreter or translated material and subsequent exclusion of those who did not speak the destination country language/s; convenience sampling (participants were often those connected to a non-government organisation working in sexual health) and social desirability bias. In some instances, studies provided little detail about country of birth, age range and other sociodemographic details, as well as legal status in host country. Most studies recruited participants from multiple countries of birth, had large age ranges and included both male and female participants, with subsequent reporting of very broad, common issues and experiences. Very few studies provided more specific detail for particular groups. Poor understanding of variations between cultures can result in incorrect assumptions about migrant health needs and subsequent low health service utilisation. Positively, all included studies sought ethical approval. 
The majority of studies $(n=12)$ reported were qualitative. As such, the association between barriers and facilitators and help-seeking outcomes were not able to be assessed. However, the qualitative nature of these studies does provide further insight into the facilitators and barriers and provided greater detail and context regarding migrants' experiences. Most studies provided detail about the methodological and theoretical framework and analysis process; however, some were limited in their reporting against best-practice reporting criteria.

Quantitative studies acknowledged the limitation of small sample sizes, with all studies recruiting less than 100 participants, and two studies less than 50. These studies focused on constructs and attitudes towards sexual health help-seeking but did not report on behavior or other help-seeking outcomes.

\subsection{Strengths and Limitations of the Systematic Review}

This systematic review is the first known study to assess sub-Saharan African and Southeast Asian migrants' sexual health help seeking in high-income countries in relation to sources of help-seeking, facilitators and barriers. The use of seven databases and multiple search terms across 17 years of peer-review literature provided a broad scope of studies. Inclusion of both quantitative and qualitative studies provided both descriptive data alongside participants' lived experiences and the context of these experiences. Multiple researchers reviewed database search results and assessed the quality of the studies for inclusion to reduce error. The review was registered with the PROSPERO International Prospective Register of Systematic Reviews. While the studies had different research questions, many of the barriers described in this review were consistent.

The limitations of this systematic review were that it included only peer-reviewed studies and those published in English. The exclusion of grey literature in this review may have limited the results, which has implications for external validity. Additionally, only articles published in English were included due to limited resources, which may have narrowed the scope of this review. It is likely that studies in other languages may have provided valuable contributions. No meta-analysis was conducted due to the heterogeneity of the included studies.

The SR only focused on high-income countries that have a universal health care system, therefore the results may not be transferable to countries such as the USA. The selected studies focused only on migrants with legal status in their destination country and there may be additional barriers for undocumented migrants. Future reviews could look at the barriers specific to undocumented migrants, as these are unique factors not relevant to documented migrants. The results of this review were context specific and are unlikely to be transferable to all sub-Saharan African and Southeast Asian migrant populations residing in high-income countries, though the findings may be valuable for a number of countries and provide broad insights and recommendations for research, policy and practice. Many of the studies included focused on barriers to health service access, making it difficult to comment on sources of help-seeking and facilitators.

This review was only interested in migrants' perspectives. It is acknowledged that studies on healthcare provider perspectives contain a rich range of information, which is not described here. Further work is planned to review this.

\section{Conclusions}

Growth in global migration has seen increases in the acquisition of STIs and BBVs amongst migrants. For migrants travelling to high-income countries from countries in regions of higher HIV prevalence, a range of factors may increase vulnerability for HIV acquisition. This study found barriers to access included: stigma relating to STIs and BBVs, direct and indirect cost associated with access, difficulty navigating health systems in destination country and lack of cultural competency within health services. Very few studies described sources of sexual health help-seeking or facilitators to help-seeking. 
Early diagnosis of STIs and BBVs is crucial to prevent onwards transmission and reduce the burden of associated healthcare. Accordingly, a better understanding is required of the structural drivers of inequality including culture and gender along with targeted, resourced and evidence-informed strategies to address these barriers.

Author Contributions: D.A.R. served as the primary author performing initial database searches and drafting the initial manuscript. G.C. and R.L. were the research supervisors conceptualizing research questions, assisting with database searching and quality appraisal, and providing critical feedback and editing of the manuscript. C.G. undertook updated searches and final article selection for inclusion in the study, drafted components of the manuscript and is the corresponding author. G.B. provided guidance on the research process and critical feedback and editing on the manuscript. All authors read and approved the final manuscript for submission.

Acknowledgments: The author would like to express appreciation to Diana Blackwood (Curtin Health Sciences Librarian) for her valuable feedback during consultation about search terms and databases. We would like to thank Yoshua Tanto for his support with database searching.

Conflicts of Interest: The authors declare no conflict of interest.

\section{References}

1. United Nations. International Migration Report 2017 (ST/ESA/SER.A/403); United Nations: New York, NY, USA, 2017.

2. The World Bank. World Bank Country and Lending Groups. Available online: https://datahelpdesk. worldbank.org/knowledgebase/articles/906519\#East_Asia_and_Pacific (accessed on 21 June 2018).

3. International Organization for Migration: Country Office for Belgium and Luxembourg. Key Migration Terms. Available online: http:/ /belgium.iom.int/key-migration-terms\%E2\%80\%8B (accessed on 15 June 2018).

4. Australian Bureau of Statistics. Overseas Born Aussies Hit a 120 Year Peak. Available online: http:/ /abs.gov. au/ausstats/abs@.nsf/latestProducts/3412.0Media\%20Release12013-14 (accessed on 5 May 2015).

5. Abraído-Lanza, A.F.; Armbrister, A.N.; Flórez, K.R.; Aguirre, A.N. Toward a theory-driven model of acculturation in Public Health Research. Am. J. Public Health 2006, 96, 1342-1346. [CrossRef] [PubMed]

6. Du, H.; Li, X. Acculturation and HIV-related sexual behaviours among international migrants: A systematic review and meta-analysis. Health Psychol. Rev. 2015, 9, 103-122. [CrossRef] [PubMed]

7. Magaña, C.G.; Hovey, J.D. Psychosocial stressors associated with Mexican migrant farmworkers in the midwest United States. J. Immigr. Health 2003, 5, 75-86. [CrossRef] [PubMed]

8. Norredam, M.; Nielsen, S.S.; Krasnik, A. Migrants' utilization of somatic healthcare services in Europe: A systematic review. Eur. J. Public Health 2010, 20, 555-563. [CrossRef] [PubMed]

9. Rademakers, J.; Mouthaan, I.; De Neef, M. Diversity in sexual health: Problems and dilemmas. Eur. J. Contracept. Reprod. Healthc. 2005, 10, 207-211. [CrossRef] [PubMed]

10. Fakoya, I.; Alvarez-del Arco, D.; Woode-Owusu, M.; Monge, S.; Rivero-Montesdeoca, Y.; Delpech, V.; Rice, B.; Noori, T.; Pharris, A.; Amato-Gauci, A.; et al. A systematic review of post-migration acquisition of HIV among migrants from countries with generalised HIV epidemics living in Europe: Implications for effectively managing HIV prevention programmes and policy. BMC Public Health 2015, 15, 561. [CrossRef] [PubMed]

11. The Kirby Institute. HIV, Viral Hepatitis and Sexually Transmissible Infections in Australia: Annual Surveillance Report 2015; The Kirby Institute, UNSW: Sydney, Australia, 2015.

12. Guy, R.J.; McDonald, A.M.; Bartlett, M.J.; Murray, J.C.; Giele, C.M.; Davey, T.M.; Appuhamy, R.D.; Knibbs, P.; Coleman, D.; Hellard, M.E. HIV diagnoses in Australia: Diverging epidemics within a low-prevalence country. Med. J. Aust. 2007, 187, 437. [PubMed]

13. Gama, A.; Fraga, S.; Dias, S. Impact of socio-demographic factors on HIV testing among African immigrants in Portugal. J. Immigr. Minor. Health 2010, 12, 841-846. [CrossRef] [PubMed]

14. Moher, D.; Liberati, A.; Tetzlaff, J.; Altman, D.G.; Group, P. Preferred reporting items for systematic reviews and meta-analyses: The PRISMA statement. PLoS Med. 2009, 6, e1000097. [CrossRef] [PubMed]

15. Leavy, J.E.; Crawford, G.; Leaversuch, F.; Nimmo, L.; McCausland, K.; Jancey, J. A Review of Drowning Prevention Interventions for Children and Young People in High, Low and Middle Income Countries. J. Commun. Health 2016, 41, 424-441. [CrossRef] [PubMed] 
16. Leavy, J.E.; Crawford, G.; Portsmouth, L.; Jancey, J.; Leaversuch, F.; Nimmo, L.; Hunt, K. Recreational drowning prevention interventions for adults, 1990-2012: A review. J. Commun. Health 2015, 40, 725-735. [CrossRef] [PubMed]

17. Crawford, G.; Lobo, R.; Brown, G.; Macri, C.; Smith, H.; Maycock, B. HIV, Other Blood-Borne Viruses and Sexually Transmitted Infections amongst Expatriates and Travellers to Low-and Middle-Income Countries: A Systematic Review. Int. J. Environ. Res. Public Health 2016, 13, 1249. [CrossRef] [PubMed]

18. Segen's Medical Dictionary. Medical Subject Headings. In The Free Dictionary; Farlex: Huntingdon Valley, PA, USA, 2012.

19. Rickwood, D.; Deane, F.P.; Wilson, C.J.; Ciarrochi, J. Young people's help-seeking for mental health problems. Aust. e-J. Adv. Ment. Health 2005, 4, 218-251. [CrossRef]

20. O'Connell, T.; Rasanathan, K.; Chopra, M. What does universal health coverage mean? Lancet 2014, 383, 277-279. [CrossRef]

21. Global Residence Index. The 2018 STC Health Index. Available online: http:/ /globalresidenceindex.com/ hnwi-index/health-index/ (accessed on 11 June 2018).

22. Australian Government Department of Home Affairs. Health Insurance. Available online: https: / / www. homeaffairs.gov.au/trav/stud/more/health-insurance (accessed on 18 June 2018).

23. Sanggaran, J.-P.; Haire, B.; Zion, D. The health care consequences of Australian immigration policies. PLoS Med. 2016, 13, e1001960. [CrossRef] [PubMed]

24. Joanna Briggs Institute. Joanna Briggs Institute Reviewers' Manual; The Joanna Briggs Institute: Adelaide, Australia, 2014.

25. National Institute for Clinical Excellence. Methods for the Development of NICE Public Health Guidance; NICE: London, UK, 2006.

26. Ussher, J.M.; Rhyder-Obid, M.; Perz, J.; Rae, M.; Wong, T.W.; Newman, P. Purity, privacy and procreation: Constructions and experiences of sexual and reproductive health in Assyrian and Karen women living in Australia. Sex. Cult. Interdiscip. Q. 2012, 16, 467-485. [CrossRef]

27. Agu, J.; Lobo, R.; Crawford, G.; Chigwada, B. Migrant Sexual Health Help-Seeking and Experiences of Stigmatization and Discrimination in Perth, Western Australia: Exploring Barriers and Enablers. Int. J. Environ. Res. Public Health 2016, 13, 485. [CrossRef] [PubMed]

28. Dune, T.; Perz, J.; Mengesha, Z.; Ayika, D. Culture Clash? Investigating constructions of sexual and reproductive health from the perspective of 1.5 generation migrants in Australia using Q methodology. Reprod. Health 2017, 14, 50. [CrossRef] [PubMed]

29. Drummond, P.D.; Mizan, A.; Brocx, K.; Wright, B. Barriers to accessing health care services for West African refugee women living in Western Australia. Health Care Women Int. 2011, 32, 206-224. [CrossRef] [PubMed]

30. McMichael, C.; Gifford, S. "It is good to know now...before it's too late": Promoting sexual health literacy amongst resettled young people with refugee backgrounds. Sex. Cult. Interdiscip. Q. 2009, 13, 218-236. [CrossRef]

31. Rogers, C.; Earnest, J. A cross-generational study of contraception and reproductive health among Sudanese and Eritrean women in Brisbane, Australia. Health Care Women Int. 2014, 35, 334-356. [CrossRef] [PubMed]

32. Korner, H. 'If I had my residency I wouldn't worry': Negotiating migration and HIV in Sydney, Australia. Ethn. Health 2007, 12, 205-225. [CrossRef] [PubMed]

33. Shangase, P.; Egbe, C.O. Barriers to Accessing HIV Services for Black African Communities in Cambridgeshire, the United Kingdom. J. Commun. Health 2014, 40, 20-26. [CrossRef] [PubMed]

34. Thomas, F.; Aggleton, P.; Anderson, J. "If I cannot access services, then there is no reason for me to test": The impacts of health service charges on HIV testing and treatment amongst migrants in England. AIDS Care 2010, 22, 526-531. [CrossRef] [PubMed]

35. Åkerman, E.; Essén, B.; Westerling, R.; Larsson, E. Healthcare-seeking behaviour in relation to sexual and reproductive health among Thai-born women in Sweden: A qualitative study. Cult. Health Sex. 2017, 19, 194-207. [CrossRef] [PubMed]

36. Adedimeji, A.A.; Asibon, A.; O'Connor, G.; Carson, R.; Cowan, E.; McKinley, P.; Leider, J.; Mallon, P.; Calderon, Y. Increasing HIV testing among African immigrants in ireland: Challenges and opportunities. J. Immigr. Minor. Health 2015, 17, 89-95. [CrossRef] [PubMed] 
37. Guionnet, A.; Navaza, B.; Pizarro de la Fuente, B.; Perez-Elias, M.J.; Dronda, F.; Lopez-Velez, R.; Perez-Molina, J.A. Immigrant women living with HIV in Spain: A qualitative approach to encourage medical follow-up. BMC Public Health 2014, 14, 1115. [CrossRef] [PubMed]

38. Manirankunda, L.; Loos, J.; Alou, T.A.; Colebunders, R.; Nöstlinger, C. “It's better not to know”: Perceived barriers to HIV voluntary counseling and testing among sub-Saharan African migrants in Belgium. AIDS Educ. Prev. 2009, 21, 582-593. [CrossRef] [PubMed]

39. Yakubu, B.D.; Simkhada, P.; Teijlingen, E.v.; Eboh, W. Sexual health information and uptake of sexual health services by African women in Scotland: A pilot study. Int. J. Health Promot. Educ. 2010, 48, 79-84. [CrossRef]

40. Lindkvist, P.; Johansson, E.; Hylander, I. Fogging the issue of HIV-Barriers for HIV testing in a migrated population from Ethiopia and Eritrea. BMC Public Health 2015, 15, 82. [CrossRef] [PubMed]

41. Manirankunda, L.; Loos, J.; Debackaere, P.; Nostlinger, C. "It is not easy": Challenges for provider-initiated HIV testing and counseling in Flanders, Belgium. AIDS Educ. Prev. 2012, 24, 456-468. [CrossRef] [PubMed]

42. United Nations. Trends in International Migrant Stock: The 2008 Revision; New York, NY, USA, 2009.

43. Kall, M.M.; Smith, R.D.; Delpech, V.C. Late HIV diagnosis in Europe: A call for increased testing and awareness among general practitioners. Eur. J. Gen. Pract. 2012, 18, 181-186. [CrossRef] [PubMed]

44. Korner, H. Late HIV diagnosis of people from culturally and linguistically diverse backgrounds in Sydney: The role of culture and community. AIDS Care 2007, 19, 168-178. [CrossRef] [PubMed]

45. The Kirby Institute. HIV, Viral Hepatitis and Sexually Transmissible Infections in Australia, Annual Surveillance Report 2016; The Kirby Institute, UNSW Sydney: Sydney, Australia, 2016.

46. Dean, J.; Mitchell, M.; Stewart, D.; Debattista, J. Intergenerational variation in sexual health attitudes and beliefs among Sudanese refugee communities in Australia. Cult. Health Sex. 2017, 19, 17-31. [CrossRef] [PubMed]

47. Dean, J.; Mitchell, M.; Stewart, D.; Debattista, J. Sexual health knowledge and behaviour of young Sudanese Queenslanders: A cross-sectional study. Sex. Health 2017, 14, 254-260. [CrossRef] [PubMed]

48. McGregor, S.; Mlambo, E.; Gunaratnam, P.; Wilson, D.; Guy, R. HIV Knowledge, Risk Behaviour and Testing: A Community Survey in People From Culturally and Linguistically Diverse (CALD) Backgrounds in NSW, Australia; The Kirby Institute UNSW Sydney: Sydney, Australia, 2017.

49. Song, A.; Richters, J.; Crawford, J.; Kippax, S. HIV and sexual health knowledge and sexual experience among Australian-born and overseas-born students in Sydney. J. Adolesc. Health 2005, 37, 243. [CrossRef] [PubMed]

50. Drummond, P.D.; Mizan, A.; Wright, B. HIV/AIDS knowledge and attitudes among West African immigrant women in Western Australia. Sex. Health 2008, 5, 251-259. [CrossRef] [PubMed]

51. Gray, C.; Crawford, G.; Reid, A.; Lobo, R. HIV knowledge and use of health services among people from South East Asia and sub-Saharan Africa living in Western Australia. Health Promot. J. Aust. 2018. [CrossRef] [PubMed]

52. Blondell, S.J.; Kitter, B.; Griffin, M.P.; Durham, J. Barriers and Facilitators to HIV Testing in Migrants in High-Income Countries: A Systematic Review. AIDS Behav. 2015, 19, 2012-2024. [CrossRef] [PubMed]

53. Alvarez-del Arco, D.; Monge, S.; Azcoaga, A.; Rio, I.; Hernando, V.; Gonzalez, C.; Alejos, B.; Caro, A.M.; Perez-Cachafeiro, S.; Ramirez-Rubio, O. HIV testing and counselling for migrant populations living in high-income countries: A systematic review. Eur. Public Health 2013, 26, 1039-1045. [CrossRef] [PubMed]

54. Collaboration for Evidence Research and Impact in Public Health. "I Want to Test but I'm Afraid": Barriers to HIV Testing among People Born in South East Asia and sub-Saharan Africa: Final Report; Curtin University: Perth, Australia, 2018.

55. Bova, C.; Nnaji, C.; Woyah, A.; Duah, A. HIV Stigma, Testing Attitudes and Health Care Access Among African-Born Men Living in the United States. J. Immigr. Minor. Health 2016, 18, 187-193. [CrossRef] [PubMed]

56. Sutton, M.Y.; Parks, C.P. HIV/AIDS Prevention, Faith, and Spirituality among Black/African American and Latino Communities in the United States: Strengthening Scientific Faith-Based Efforts to Shift the Course of the Epidemic and Reduce HIV-Related Health Disparities. J. Relig. Health 2013, 52, 514-530. [CrossRef] [PubMed]

57. Hood, J.E.; Friedman, A.L. Unveiling the hidden epidemic: A review of stigma associated with sexually transmissible infections. Sex. Health 2011, 8, 159-170. [CrossRef] [PubMed] 
58. Drummond, P.D.; Mizan, A.; Brocx, K.; Wright, B. Using peer education to increase sexual health knowledge among West African refugees in Western Australia. Health Care Women Int. 2011, 32, 190-205. [CrossRef] [PubMed]

59. Mengesha, Z.B.; Dune, T.; Perz, J. Culturally and linguistically diverse women's views and experiences of accessing sexual and reproductive health care in Australia: A systematic review. Sex. Health 2016, 13, 299-310. [CrossRef] [PubMed]

60. Mengesha, Z.B.; Perz, J.; Dune, T.; Ussher, J. Refugee and migrant women's engagement with sexual and reproductive health care in Australia: A socio-ecological analysis of health care professional perspectives. PLoS ONE 2017, 12, e0181421. [CrossRef] [PubMed]

61. Johnson, D.R.; Ziersch, A.M.; Burgess, T. I don't think general practice should be the front line: Experiences of general practitioners working with refugees in South Australia. Aust. N. Z. Health Policy 2008, 5, 20. [CrossRef] [PubMed]

62. Boateng, L.; Nicolaou, M.; Dijkshoorn, H.; Stronks, K.; Agyemang, C. An exploration of the enablers and barriers in access to the Dutch healthcare system among Ghanaians in Amsterdam. BMC Health Serv. Res. 2012, 12, 75. [CrossRef] [PubMed]

63. Sheikh-Mohammed, M.; MacIntyre, C.R.; Wood, N.J.; Leask, J.; Isaacs, D. Barriers to access to health care for newly resettled sub-Saharan refugees in Australia. Med. J. Aust. 2006, 185, 594-597. [PubMed]

64. Ogilvie, L.D.; Burgess-Pinto, E.; Caufield, C. Challenges and approaches to newcomer health research. J. Transcult. Nurs. 2008, 19, 64-73. [CrossRef] [PubMed]

65. Wilson, D.; Neville, S. Culturally safe research with vulnerable populations. Contemp. Nurse 2009, 33, 69-79. [CrossRef] [PubMed]

66. Henderson, S.; Kendall, E. Culturally and linguistically diverse peoples' knowledge of accessibility and utilisation of health services: Exploring the need for improvement in health service delivery. Aust. J. Prim. Health 2011, 17, 195-201. [CrossRef] [PubMed]

67. Burns, F.M.; Imrie, J.Y.; Nazroo, J.; Johnson, A.M.; Fenton, K.A. Why the(y) wait? Key informant understandings of factors contributing to late presentation and poor utilization of HIV health and social care services by African migrants in Britain. AIDS Care 2007, 19, 102-108. [CrossRef] [PubMed]

68. Botfield, J.R.; Newman, C.E.; Zwi, A.B. Drawing them in: Professional perspectives on the complexities of engaging 'culturally diverse' young people with sexual and reproductive health promotion and care in Sydney, Australia. Cult. Health Sex. 2017, 19, 438-452. [CrossRef] [PubMed]

69. Deblonde, J.; De Koker, P.; Hamers, F.F.; Fontaine, J.; Luchters, S.; Temmerman, M. Barriers to HIV testing in Europe: A systematic review. Eur. J. Public Health 2010, 20, 422-432. [CrossRef] [PubMed]

70. Driver, G.; Debattista, J.; Gu, Z.; Lemoire, J.; Hooper, J. HIV testing within the African community using home-based self collection of oral samples. Aust. N. Z. J. Public Health 2017, 44, 446. [CrossRef] [PubMed] 